\title{
KEBAHAGIAAN DAN KOMITMEN ORGANISASI PADA ORGANISASI MAHASISWA
}

\author{
Yosafat Waluyo ${ }^{1}$
}

\author{
Andhika Alexander Repi ${ }^{2}$ \\ yosafatwaluyo@gmail.com \\ andhika@ukwms.ac.id
}

Fakultas Psikologi Universitas Katolik Widya Mandala Surabaya

\begin{abstract}
Abstrak
Komitmen organisasi merupakan hubungan, keyakinan dan penerimaan individu terhadap nilai-nilai dalam organisasi yang diikutinya. Kebahagiaan merupakan emosi positif yang mempengaruhi kualitas hidup seseorang dan dapat mempengaruhi peningkatan baik kinerja fisik dan psikologi seseorang. Penelitian ini bertujuan untuk mengetahui hubungan antara kebahagiaan dengan komitmen organisasi pada anggota Organisasi Mahasiswa (Ormawa). Penelitian ini dilakukan pada ormawa Fakultas Psikologi Universitas katolik Widya Mandala Surabaya, dengan partisipan (N=35) anggota Ormawa Fakultas Psikologi tahun 2017/2018. Pengambilan data dilakukan dengan teknik total population sampling. Pengumpulan data dilakukan dengan menggunakan Skala Kebahagiaan dengan 6 dimensi, dan Skala Komitmen Organisasi dengan 3 dimensi dan dianalisis dengan menggunakan teknik statistika nonparametrik Kendall Tau B. Hasil pengolahan data mendapatkan sig sebesar $0,341(\mathrm{p}>0,05)$ yang berarti tidak ada hubungan antara kebahagiaan dengan komitmen organisasi pada Ormawa Fakultas Psikologi Universitas Katolik Widya Mandala Surabaya. Secara deskriptif tingkat kebahagiaan anggota ormawa tergolong sedang hingga sangat tinggi dan sebagian besar anggota ormawa memiliki tingkat kebahagiaan yang sedang yaitu sebesar $60 \%$ dan sebagian besar anggota ormawa memiliki tingkat komitmen organisasi yang sedang yaitu sebesar $45,7 \%$.
\end{abstract}

Kata Kunci: Kebahagiaan, Komitmen organisasi, Organisasi Mahasiswa

\begin{abstract}
Organizational commitment is relations, beliefs, and self acceptance to organization culture and values. Happiness is a positive emotion that can affect one's quality of life, and physical and psychological performances. This study aimed to examine the correlation between happiness and organizational commitment among student organization members. This research was conducted at Widya Mandala Catholic University in Surabaya. Participans $(N=35)$ were psychology student organization members $(2017 / 2018$ period). Data were collected by total population sampling method. Data collection was carried out using happiness scale and organizational commitment scale. Data were analyzed using Kendall Tau B analysis. Result showed there were no correlation between happiness and organizational commitment among student organization members at the Faculty of Psychology, Widya Mandala Catholic University in Surabaya ( $p=0,341 ; p>0,05)$. Descriptively, the happiness levels of student organization members ranged from moderate to very high, with most of the members had a moderate level of happiness of $60 \%$ and most student organization members had moderate level of organizational commitment at 45,7\%.
\end{abstract}


Keywords: Happiness, Organization commitment, Student organization

\section{Pendahuluan}

Remaja merupakan masa ketika individu mulai mencari identitas dirinya. Menurut teori perkembangan yang dikemukakan oleh Erikson (Santrock, 2002) pada masa ini seorang individu yang memasuki tahap perkembangan remaja akan dihadapkan pada penjajakan diri dan karier yang akan dibangun oleh dirinya. Begitu juga pada saat seorang remaja menempuh jenjang perkuliahan, para mahasiswa berusaha untuk aktif dalam organisasi yang ada pada universitas maupun fakultas. Mahasiswa yang terlibat di organisasi seharusnya memiliki kontribusi yang optimal. Kinerja bisa berupa kesuksesan individu dalam menyelesaikan pekerjaannya (Setiawan, 2015). Kinerja yang optimal dari anggota organisasi, dapat membantu organisasi untuk mencapai tujuannya.

Anggota organisasi yang memiliki kinerja yang optimal cenderung memiliki komitmen organisasi yang baik (Luthans, 2002). Komitmen organisasi adalah hubungan seorang individu dengan organisasi yang sedang diikutinya Mowdy (Robbins, 2005). Komitmen ini memiliki fungsi untuk mengikat individu pada suatu organisasi. Individu yang terindikasi memiliki komitmen organisasi memunculkan keterlibatan yang aktif dalam organisasi, sedangkan individu yang terindikasi tidak menunjukkan adanya komitmen organisasi cenderung tidak ingin terlibat dalam organisasi.

Komitmen dalam organisasi berfungsi untuk membuat kelekatan antara organisasi dengan anggotanya. Komitmen juga berfungsi untuk meningkatkan kinerja dari individu dalam organisasi. Komitmen organisasi cenderung dimiliki oleh individu yang memiliki kebahagiaan (Sherlywati, 2015). Kebahagiaan adalah emosi positif yang dirasakan individu melalui berbagai pengalaman secara positif (Frederickson dalam Compton, 2005). Kebahagiaan menimbulkan keterlibatan secara sukarela individu terhadap organisasinya. Hal ini nantinya akan meningkatkan komitmen yang berdampak pada peningkatan kinerja.

Komitmen organisasi adalah salah satu bentuk komitmen dengan memiliki fokus yang berbeda (Allen \& Meyer, 1997). Mowdy, Porter, dan Streers (dalam Robbins, 2005) menyatakan bahwa komitmen organisasi adalah sifat hubungan seorang individu dengan organisasi dimana dia berada. Hubungan individu dengan organisasi terkait kontrak kerja, peraturan dalam organisasi, dan nilai-nilai yang ada dalam organisasi. Semakin individu berfokus dengan organisasi yang diikuti, semakin baik komitmennya dalam organisasi (Tolentino, 2013). Komitmen organisasi merupakan keyakinan dan penerimaan terhadap nilai dan tujuan organisasi dengan secara sadar mencurahkan usaha demi kepentingan organisasi (Griffin \& Bateman, dalam Spector, 2012). Komitmen organisasi juga merupakan dambaan pribadi untuk mempertahankan keanggotaannya dalam organisasi. Dari definisi tersebut dapat disimpulkan bahwa komitmen organisasi merupakan hubungan antara anggota organisasi dengan organisasi yang diikutinya, yang memunculkan keyakinan untuk bertahan dalam organisasi, dan penerimaan individu terhadap nilai-nilai dalam organisasi yang diikuti.

Terdapat 3 aspek dalam komitmen organisasi menurut Allen dan Meyer (1997). Affective commitment menunjukkan suatu kelekatan psikologi terhadap organisasi, pada komitmen ini muncul keterlibatan antara individu dan organisasi. Komitmen ini membuat anggota organisasi bertahan karena adanya keterikatan secara emosional dengan organisasi yang diikutinya. Normative commintment ditunjukkan dengan perasaan wajib untuk tetap bertahan di organisasi. Anggota yang bertahan karena komitmen ini biasanya memiliki nilai-nilai dan norma yang tinggi pada dirinya dan merasa harus tinggal 
dalam organisasi tersebut karena hal tersebut adalah benar. Continuance commitment adalah kesadaran akan ketidakmungkinan memilih identitas sosial lain ataupun alternatif tingkah laku lain karena adanya ancaman akan kerugian. Anggota yang memiliki komitmen ini bertahan di suatu organisasi karena mereka membutuhkan keuntungan yang diberikan oleh organisasi dan tidak bisa menemukan organisasi lain yang sesuai dengan kemampuan mereka.

Menurut Argyle, Martin dan Crossland (Anggoro \& Widhiarso, 2010), kebahagiaan adalah gambaran laten secara umum yang diindikasikan melalui tingkat kepuasan hidup. Kebahagiaan juga didefinisikan sebagai kepuasan hidup yang menyeluruh. Bagi anggota organisasi mahasiswa, kebahagiaan dapat dilihat dari seberapa tinggi tingkat kepuasannya dalam menyelesaikan tugasnya dalam organisasi mahasiswa. Kebahagiaan merupakan suatu unsur dari kesejahteraan dan salah satu dari emosi positif. Menurut Frederickson (dalam Compton, 2005), semakin sering seseorang merasakan emosi yang positif dapat membuat individu memiliki personal resources yang membantu individu melalui berbagai pengalaman secara positif dan tetap merasa positif dalam setiap emosi yang dia rasakan. Menurut Diener (Compton, 2005) kebahagiaan merupakan kualitas dari kehidupan manusia peningkatkan kebahagiaan dapat mempengaruhi kualitas hidup seseorang secara keseluruhan dan membuat individu gembira dengan apa yang diperolehnya, seperti kesehatan yang lebih baik, gembira terhadap pencapaian yang diperolehnya. Kebahagiaan dapat memberikan keuntungan jika dilakukan dalam jangka waktu yang panjang yaitu peningkatan daya tahan, intelektual, dan social resources. Anggota organisasi yang bahagia dapat dilihat dari peningkatan daya tahan, intelektual, dan social resourcesnya. Dari definisi tersebut, maka peneliti menyimpulkan bahwa kebahagiaan adalah emosi positif yang mempengaruhi kualitas hidup seseorang dan dapat mempengaruhi peningkatan baik kinerja fisik dan psikologi seseorang.

Menurut Argyle, Martin dan Crossland terdapat beberapa aspek yang mempengaruhi kebahagiaan seseorang (Hill \& Argyle, 2002), seperti life satisfaction yang mencakup kepuasan dalam hidup, kepuasan akan pencapaian-pencapaiannya. Individu akan cenderung lebih menerima semua hal yang ada dalam kehidupannya. Joy mencakup penerimaan diri, mengalami keceriaan dan kegembiraan dengan orang lain, bergairah dalam hidup, banyak tertawa, merasa bahagia, mudah mengambil keputusan. Self-esteem mencakup seperti merasa dunia itu indah, berkomitmen dan berpengaruh, terlihat energik, merasa hidup itu menyenangkan, selalu percaya hal yang dilakukan dapat berdampak positif. Calm mencakup kewaspadaan secara mental, dapat mengatur waktu, dapat melihat lingkungan sekitar dengan lebih tenang. Control mencakup kondisi mengontrol diri sendiri, mengontrol energi-energi yang akan dikeluarkan. Efficacy mencakup kemampuan untuk melihat keindahan dalam beberapa hal.

Di satu sisi, penelitian yang mengkaitkan kedua variabel ini cenderung mengacu pada organisasi berupa perusahaan dan masih jarang yang membahas mengenai konsep kebahagiaan dan komitmen organisasi dalam ranah organisasi non-profit seperti organisasi mahasiswa. Di sisi lain, kebahagiaan dan komitmen organisasi merupakan variabel dasar yang penting dalam keberhasilan suatu organisasi manapun termasuk organisasi mahasiswa. Martin Seligman menyatakan ketika seorang anggota organisasi berbahagia, maka akan ada suatu drive atau dorongan agar lebih berkomitmen dengan tugas, pekerjaan, serta perannya terhadap organisasi. Seseorang yang berbahagia juga akan menunjukkan kinerja terbaiknya di dalam organisasinya. Demikian pula, ketika anggota tersebut memiliki komitmen organisasi yang tinggi, maka cara pandangnya terhadap organisasi 
cenderung positif dan bahkan akan memberikan hal terbaik bagi organisasinya (Sherlywati, 2015). Oleh sebab itu, peneliti akan membuat sebuah penelitian terkait hubungan kebahagiaan dengan komitmen organisasi pada Organisasi Mahasiswa. Penelitian ini diharapkan mampu memberikan sumbangsih teoritis secara khusus bagi pengembangan keilmuan psikologi organisasi. Selain itu, secara praktis, penelitian ini pun dapat menjadi referensi bagi pihak Fakultas khususnya organisasi kemahasiswaan untuk mengidentifikasi kebahagiaan dan komitmen organisasi yang ada di organisasi ini sehingga dapat membuat langkah strategis agar organisasi menjadi lebih optimal.

\section{Metode Penelitian Partisipan}

Teknik pengambilan sampel dalam penelitian ini menggunakan Total Population Sampling. Jumlah anggota Organisasi Mahasiswa di Fakultas Psikologi Universitas Katolik Widya Mandala Surabaya berjumlah kurang dari 100 orang maka sampel diambil secara keseluruhan sehingga total sampel berjumlah 35 orang.

\section{Alat Ukur Penelitian}

Metode pengumpulan data ini menggunakan Skala Kebahagiaan dan Skala Komitmen Organisasi. Skala ini bertujuan untuk mengungkap kebahagiaan dan komitmen organisasi pada anggota Organisasi Mahasiswa Fakultas Psikologi Universitas Katolik Widya Mandala Surabaya Aitem-aitem yang ada dalam skala ini disusun menggunakan modifikasi Skala Likert yang meliputi 2 jenis aitem yaitu favorable dan unfavorable yang disebar dalam Skala Komitmen Organisasi dan Skala Kebahagiaan. Masing-masing respon dibagi menjadi 4 alternatif pilihan jawaban dengan skor yang berbeda. Setiap aitem memiliki empat alternatif jawaban, yaitu "Sangat Setuju" (SS), "Setuju" (S), "Tidak Setuju" (TS), "Sangat Tidak Setuju" (STS). Masing-masing bobot nilai untuk pernyataan favorable adalah $\mathrm{SS}=4, \mathrm{~S}=3$, $\mathrm{TS}=2$, $\mathrm{STS}=1$, sedangkan bobot nilai untuk pernyataan unfavorable adalah $\mathrm{SS}=1, \mathrm{~S}=2$, $\mathrm{TS}=3, \mathrm{STS}=4$. Jumlah aitem pada Skala Kebahagiaan, yaitu 24 Aitem, sedangkan Skala Komitmen Organisasi memiliki 24 aitem.

Skala Komitmen Organisasi memiliki nilai Cronbach's Alpha sebesar 0.769 dengan nilai corrected item-total correlation berada pada rentang 0.302 0.638 dengan jumlah aitem valid 6 aitem. Sedangkan, Skala Kebahagiaan memiliki nilai Cronbach's Alpha sebesar 0.719 dengan nilai corrected item-total correlation berada pada rentang 0.2680.504 dengan jumlah aitem valid 11 aitem.

\section{Teknik Analisis Data}

Sebelum melakukan uji kolerasi, peneliti melakukan uji asumsi yang terdiri dari uji normalitas dan uji linieritas dari data-data yang ada. Berdasarkan uji normalitas, variabel kebahagiaan mendapatkan nilai sig sebesar 0.190 ( $\geq$ 0.05) dan variabel komitmen organisasi mendapatkan nilai sig sebesar 0.173 ( $\geq$ 0.05), sehingga, kedua variabel tergolong normal. Berdasarkan hasil uji linieritas yang dilakukan pada kedua variabel diperoleh nilai sig sebesar $0.385(\geq 0.05)$, sehingga data tergolong tidak linier. Oleh sebab itu, peneliti akan menggunakan analisa data non-parametrik Kendall's Tau$b$ untuk mengetahui hubungan antar variabel (Santoso, 2001).

\section{Hasil Penelitian}

Berdasarkan hasil uji statistik nonparametrik dengan menggunakan uji korelasi Kendall's tau $b$ antara variabel kebahagiaan dan variabel komitmen organisasi didapatkan nilai signifikansi sebesar 0,148 $(p>0,05)$ yang berarti tidak terdapat hubungan antara variabel kebahagiaan dan variabel komitmen organisasi pada anggota organisasi mahasiswa Fakultas Psikologi Universitas Widya Mandala Surabaya. 
Hasil penelitian ini berbanding terbalik dengan beberapa penelitian sebelumnya. Penelitian yang dilakukan oleh Aris (2014) menunjukkan hasil yang kontradiktif dengan hasil penelitian ini. Aris (2014) menggunakan kebahagiaan yang dikemukakan oleh Diener yaitu subjective well-being. Penelitian yang dilakukan oleh Yarameshlu, Darvish, dan Sadaghiani (2015) juga menggunakan kebahagiaan yang dikemukakan oleh Diener yang mengarah ke subjective wellbeing. Kedua penelitian tersebut menggunakan variabel kebahagiaan yang berbeda dengan penelitian ini.

Variabel kebahagiaan yang digunakan peneliti adalah kebahagiaan yang dikemukakan oleh Hill dan Argyle (2002) sedangkan, variabel kebahagiaan yang dikemukakan oleh Diener dan oleh Hill dan Argyle memiliki aspek pembentuk yang berbeda. Hal tersebut berpotensi mempengaruhi hasil penelitian antara penelitian ini dengan penelitian sebelumnya. Diener (dalam Compton, 2005) berfokus pada kebahagiaan yang dirasakan individu berdasarkan tolak ukur kebahagiaan yang dimiliki individu itu sendiri. Kebahagiaan Hill dan Argyle (2002) berfokus pada kebahagiaan yang dimiliki oleh individu dan yang individu terima dari luar dirinya.

Hasil penelitian lain yang kontradiktif dengan hasil penelitian ini adalah penelitian yang dilakukan oleh Boroujeni (2012) yang mengambil subjek pada organisasi profit. Begitu pula dengan penelitian yang dilakukan oleh Boroujeni dan Hematian (2017) juga mengambil subjek sejenis. Pada penelitian ini, peneliti mengambil subjek penelitian pada organisasi non-profit. Hal tersebut dapat berpotensi mempengaruhi hasil penelitian. Menurut Allen dan Mayer (1997) salah satu faktor pembentuk komitmen organisasi merupakan kepuasan kerja dimana pada kepuasan kerja terdapat salary sebagai tolak ukur apakah individu tersebut merasa puas dalam organisasinya.

Berdasarkan faktor kepuasan kerja, organisasi profit dan non-profit memiliki sumber kepuasan yang berbeda. Untuk organisasi profit dipengaruhi banyak hal, salah satunya salary. Namun di organisasi non-profit terdapat juga faktor yang mempengaruhi kepuasan kerja, salah satunya motivasi kerja (Rosalino, 2013). Adapun jika individu selalu termotivasi, maka dirinya akan merasa puas dalam melakukan perkerjaannya dalam organisasi.

Selain itu, Universitas Katolik Widya Mandala Surabaya memiliki satu nilai yaitu PeKA yaitu Peduli, Komit, dan Antusias. Nilai-nilai ini dihayati oleh seluruh warga universitas. Nilai tersebut juga diterapkan dalam organisasi yang ada dalam universitas dan fakultas. Nilai peduli dalam organisasi mahasiswa dapat memunculkan semangat saling membantu dan kenyamanan antar anggota. Hal tersebut dapat membuat anggota organisasi lebih bahagia dalam organisasinya. Nilai komit membuat anggota organisasi untuk berkomitmen dalam organisasinya. Hal tersebut dapat memunculkan komitmen organisasi pada anggota organisasi mahasiswa. Nilai antusias membuat anggota selalu bersemangat dalam melaksanakan tugas di organisasi. Nilai ini memunculkan komitmen organisasi juga.

Secara deskriptif, tingkat kebahagiaan pada anggota mahasiswa Fakultas Psikologi Universitas Katolik Widya Mandala Surabaya berada pada rentang sedang hingga sangat tinggi. Namun, secara umum, para anggota merasa cukup berbahagia di dalam organisasi ini (60\% Kebahagiaan berada pada tingkat sedang). Ada banyak faktor yang menyebabkan para mahasiswa menjadi bahagia ketika berdinamika di dalam organisasi ini. Di dalam organisasi ini, para mahasiswa mampu menyalurkan ide, pemikiran, saran dan pendapat dalam rangka pengembangan organisasi. Relasi antar anggota organisasi yang dirasa sebagai suatu keluarga pun makin meningkatkan kebahagiaan ketika berdinamika di dalam organisasi Hill dan Argyle (2002), namun perbedaan pendapat yang cukup sering terjadi dalam proses 
rapat atau di dalam kesehariannya, tugastugas yang menumpuk antara tugas kuliah serta tugas organisasi, serta konflik yang terjadi di dalam organisasinya menyebabkan rentang kebahagiaan secara umum dari anggota organisasi kurang mampu mencapai tahap tinggi (Compton, 2005; Aris, 2014)

Tingkat komitmen organisasi pada anggota mahasiswa Fakultas Psikologi Universitas Katolik Widya Mandala Surabaya berada pada rentang kategori sangat rendah hingga sangat tinggi. Secara umum, komitmen organisasi para mahasiswa yang merupakan anggota organisasi ini berada pada kategori sedang (45.7\%). Komitmen organisasi yang berada pada kategori sedang berarti para anggota organisasi sudah mau melakukan tugas tanggung jawab sesuai deskripsi pekerjaannya masing-masing. Para anggota pun cukup mau berpartisipasi di dalam berbagai aktivitas dan dinamika organisasi, termasuk memberikan pendapat atau ide pengembangan (Sherlywati, 2015).

Hasil penelitian ini menemukan bahwa ada beberapa mahasiswa yang memiliki tingkat komitmen organisasi yang masih sangat rendah. Peneliti tidak secara khusus menggali secara kualitatif mengapa masih ada kecenderungan partisipan yang memiliki kategori sangat rendah ini. Inilah yang kemudian menjadi salah satu kelemahan penelitian yang harus segera ditindak lanjuti oleh pendamping organisasi. Anggota organisasi yang memiliki komitmen rendah cenderung enggan melakukan tugasnya secara maksimal dan dapat berpotensi menggangu kinerja organisasi secara umum (Allen \& Mayer, 1997; Luthans, 2002; Tolentino, 2013).

Berdasarkan data tabulasi silang (distribusi frekuensi) antara kebahagiaan dengan jenis kelamin dapat dilihat bahwa sebagian partisipan memiliki tingkat kebahagiaan yang tinggi (sangat tinggitinggi) dengan proposi antara jenis kelamin laki-laki dan perempuan $11,4 \%$ dan $20,1 \%$, dapat dikatakan bahwa partisipan dengan jenis kelamin perempuan mungkin lebih bahagia dari pada partisipan dengan jenis kelamin laki-laki. Data tabulasi silang antara komitmen organisasi dengan jenis kelamin menunjukkan adanya kesesuaian dengan penelitian yang dilakukan oleh Rizki \& Rahmi (2013) dimana jenis kelamin perempuan memiliki tingkat komitmen organisasi yang tinggi.

Distribusi data pada tabel tabulasi silang antara kebahagiaan dengan jenis organisasi membuktikan teori kebahagiaan yang dikemukakan oleh Argyle (dalam Anggoro \& Widhiarso, 2010), dimana Badan Perwakilan Mahasiswa (BPM) menjadi organisasi dengan tingkat kebahagiaan yang lebih baik dari organisasi yang lain. BPM memiliki karakteristik yang hampir sama dengan aspek-aspek yang dikemukakan oleh Hill \& Argyle (2002). Salah satunya adalah joy, dimana dalam BPM terdapat kebahagiaan sesama anggota, dan keceriaan dalam organisasinya. Pada tabel komitmen organisasi dengan jenis organisasi, BPM memiliki komitmen organisasi yang paling baik di antara organisasi mahasiswa yang ada. Selain itu, BPM juga memiliki kebahagiaan yang paling baik. Hal ini memperkuat teori yang dikemukakan oleh Allen dan Mayer (1997). Teori ini menyatakan bahwa komitmen organisasi muncul akibat adanya kelekatan antar individu dalam organisasinya.

\section{Kesimpulan}

Berdasarkan hasil penelitian dapat disimpulkan bahwa tidak ada hubungan yang signifikan antara kebahagiaan dengan komitmen organisasi pada anggota organisasi mahasiswa Fakultas Psikologi Universitas Katolik Widya Mandala Surabaya.

Tingkat kebahagiaan pada anggota organisasi mahasiswa Fakultas Psikologi Universitas Katolik Widya Mandala Surabaya berada pada rentang dari Sedang (S) hingga Sangat Tinggi (ST). Tingkat kebahagiaan pada anggota organisasi mahasiswa Fakultas Psikologi Universitas Katolik Widya Mandala Surabaya 
didominasi oleh rentang Sedang (S) yaitu sebanyak $60 \%$ atau 21 partisipan.

Tingkat komitmen organisasi pada anggota organisasi mahasiswa Fakultas Psikologi Universitas Katolik Widya Mandala Surabaya, berada pada rentang dari Sangat Rendah (SR) hingga Sangat Tinggi (ST). Tingkat komitmen organisasi pada anggota organisasi mahasiswa Fakultas Psikologi Universitas Katolik Widya Mandala Surabaya didominasi pada rentang Sedang (S) yaitu sebanyak 45,7\% atau 16 partisipan.

\section{Keterbatasan dan saran}

Hasil penelitian ini dapat menjadi referensi bagi dekanat dan dosen pendamping organisasi mahasiswa untuk mengembangkan kegiatan untuk pengembangan nilai-nilai PeKA dalam organisasi mahasiswa. Hal ini dikarenakan nilai PeKA mungkin dapat membantu anggota organisasi mahasiswa untuk meningkatkan kebahagiaan dan komitmen dalam organisasi mahasiswa. Penelitian ini dapat menjadi bahan refleksi untuk anggota organisasi mahasiswa Fakultas Psikologi, Universitas Katolik Widya Mandala Surabaya sebagai upaya peningkatan kebahagiaan dan komitmen di dalam organisasinya masing-masing. Penelitian ini dapat menjadi salah satu bahan referensi bagi penelitian selanjutnya. Diharapkan, penelitian selanjutnya dapat mengambil subjek yang lebih banyak, dapat memperhatikan jumlah aitem valid agar alat ukur memang mampu merepresentasikan variabel yang akan diukur.

\section{Daftar Pustaka}

Allen, N. J. \& Meyer, J. P. (1997). Commitment in the work place: Theory, research, and application. California: SAGE Publication, Inc.

Anggoro \& Widhiarso. (2010). Konstruksi dan identifikasi properti psikometris instrumen pengukuran kebahagiaan berbasis pendekatan indigenous psychology: Studi multitrait multimethod. Jurnal Psikologi, 37(2). Diakses pada pada Kamis 12 Oktober 2017 dari

http://jurnal.ugm.ac.id/jpsi/article/downloa $\underline{\mathrm{d} / 7728 / 5978}$

Aris, I K. (2014). Hubungan komitmen organisasi dengan subjective well-being (SWB) karyawan pada karyawan produksi CV. Putra Buana Surakarta. (Skripsi). Diakses pada Sabtu, 17 Februari 2018 dari http://repository.uksw.edu/ handle/12345678/8982

Boroujeni, I. N. (2012). Relationship between happiness and organizational commitment of the employees of youth and sports Departemen of Chahar mahal and Bakhtiari province, International Journal of Sport Studies, 2 (9). Diakses dari http://ijssjournal.com/ fulltext/paper04012016143534.pdf

Boroujeni, I. N. \& Hematian, A, (2017). Study of relationship between happines and organizational commitment of office in youth and sport ministry in Iran, International journal of sport studies, 4 (60), 733-737. Diakses pada Rabu, 5 Juli 2017 dari http://ijssjournal.com/fulltext/ paper-09012016134059.pdf

Compton, C. W. (2005). An introduction to positive psychology. USA: Thomson Wadworth.

Hills, P. \& Argyle, M. (2002). The Oxford Happiness Questionnaire: A compact scale for the measurement of psychological well-being. Personality and Individual differences, 33, (7), 1073-1082. Diakses dari http://www.elsevier.com/locate/paid

Luthans, F. (2002). Organizational behavior: $7^{\text {th }}$ edition. New York: McGraw Hill Inc.

Rizki, A. P. L, \& Rahmi. (2013). Perbedaan komitmen organisasi ditinjau dari gender karyawan PT. indomarco prismata Medan. Psikologia, 8 (1), 19-24). Diakses dari https://jurnal.usu.ac.id/ index.php/psikologia/article/viewFile/6594 12756

Robbins, P. (2005). Essentials of organizational behavior. New Jersey: Pearson education. 
Rosalino, F. (2013). Pengaruh budaya organisasi dan motivasi terhadap kepuasan kerja staf internal pada organisasi non profit. Jurnal Ilmu Ekonomi dan Sosial, 2 (2), 185-194.

Santoso, S. (2001). Buku latihan SPSS statistik parametrik. Jakarta: Elex media komputindo.

Santrock, J. W. (2002). Life span development. Jakarta: Erlangga.

Setiawan, K. C. (2015). Pengaruh motivasi kerja terhadap kinerja karyawan level pelaksana di divisi operasi PT. Pursi Palembang. Jurnal Psikologi Islami, 1(2), 43-53. Diakses dari http://jurnal.radenfatah.ac.id/index.php/psi kis/article/download/567/504

Sherlywati. (2015). Komitmen organisasional dan authentic happiness: Studi kasus karyawan pada sebuah organisasi bisnis retail di kota Bandung. Jurnal Administrasi Bisnis, 11(1), 33-60. Diakses dari http://journal.unpar.ac.id/index.php/Jurnal AdministrasiBisnis/article/download/1705/ 1622

Spector, E. P. (2012). Industrial and organizational psychology research and practice. Florida: Department of psychology, University of South Florida

Tolentino, C. R. (2013). Organizational commitment and job performance of the academic and administrative personel. International Journal of Information Technology and Business Management, 15 (1). Diakses dari http://www.jitbm.com/

JITBM\%2015\%20volume/5\%20Organizati on $\% 20$ Commitment.pdf

Yarameshlu, Z., Darvish, A. Z., \& Sadaghiani, S. J. (2015). Review of factor affecting organizational commitment with the approach of desire for happiness in agricultural bank headquarter in Tehran. Applied Mathematics in Engineering, Management and Technology, 3(3). Diakses dari http:/amiemtjournal.com/test/vol3-3/7.p 